\title{
Improving the Management of Environmental Engineering Projects through The Best Value Project Management Model (BV PMM) for The Arizona Department of Environmental Quality
}

\author{
Dean Kashiwagi ${ }^{1}$, Alfredo Rivera ${ }^{2}$, \\ ${ }^{1}(P h D, P E),{ }^{2}(M . S$.$) Arizona State University, Tempe, A Z$
}

\begin{abstract}
The Arizona Department of Environmental Quality (ADEQ) is the regulatory agency responsible for ensuring quality of air, land, and water resources. Historically, $A D E Q$ has experienced difficulty in managing environmental professional services. To potentially address the issues, ADEQ tested a new approach to managing their projects, the Best Value Project Management Model (BV PMM), which focuses on using logic and natural laws instead of technical information and experience to improve project performance. This paper presents a case study on ADEQ's implementation of the BV PMM on their indefinite delivery indefinite quantity (IDIQ) Arizona Superfund Response Action Contract (ASRAC) that is utilized by the Water Quality Assurance Revolving Fund (WQARF) contract that ran 60 individual projects. The main function of the WQARF program is to identify, assess and remediate sites that are contaminated with hazardous substances. This paper presents the BV PMM, its development, and documents the case study results after one year of implementation. Results include an improved PM utilization rate (22\% increase), increase in vendor work performed (102\%) in 33\% less time, and increase in customer satisfaction (22\%).
\end{abstract}

Keywords: Best Value Project Management Model, ADEQ, Best Value PIPS, traditional

\section{Introduction}

The Arizona Department of Environmental Quality (ADEQ) is the environmental regulatory agency for Arizona $\left(16^{\text {th }}\right.$ largest state in U.S.), covering a population of 6.8 million people. Its mission is to protect and enhance public health, welfare and the environment in Arizona. Established by the Arizona Legislature in 1986 in response to growing concerns about groundwater quality, ADEQ today administers a variety of programs to improve the health and welfare of its citizens and to ensure the quality of Arizona's air, land and water resources meet regulatory standards. With an average of 400 employees managing various contaminants and pollutants, ADEQ strives to lead Arizona and the nation in protecting the environment and improving the quality of life for the people in the State of Arizona (ADEQ, 2015).

Over the last decade, ADEQ has tried to make the changes necessary to accomplish its mission, but has been having difficulties with the performance of their environmental professional services. The upper management at ADEQ identified the following problems:

1. Unable to identify performance and value of vendors / environmental experts.

2. Vendors were not meeting the quality expectations of ADEQ.

3. Management requirement of the vendors was too high.

4. Inability to spend all available resources.

Most of the issues ADEQ was experiencing were common among environmental quality projects. Environmental projects are expensive, complex in nature and often times require multiple testing and invasive investigations over a period of many years before the final end goal of the project can be clearly defined. This makes it difficult to clearly set expectations and plan resource requirements, causing inaccurate expectations of the time, cost, and quality of projects. The lack of important pieces of information at the beginning of a project also increases the risk of the project. This is an issue that has been plaguing the environmental engineering industry and many others worldwide for decades (Vaughn and Ardila, 1993; Filipovich, 2001; Esty \& Porter, 2005; International Rivers, 2005; Macek, 2006; Reuters 2009; Bo-Jie, et al., 2010; Fu et al., 2010; Buntaine, et al., 2013; Fisher, 2013; IEG, 2013; Padgett, 2014; AFP 2014).

\section{Problem}

ADEQ began deploying Lean principles in 2013, which geared staff toward eliminating waste and increasing value for its customers by improving internal systems and processes. The WQARF program has implemented process improvements to accelerate clean-ups, engage responsible parties and ultimately reduce the overall costs of remediating contaminated sites. ADEQ lacked a consistent contracting and project management mechanism that paralleled the process improvements that the agency was implementing. As the 
WQARF ASRAC contract was coming up for re-bid, ADEQ desired a process that would accurately identify the quality and performance of the environmental work being completed, and promote their vendors and internal personnel to be more proactive and accountable for their work to achieve their accelerated cleanup model. Some of the difficulties ADEQ faced in doing this are as follows:

1. ADEQ lacked the number of in-house project managers to perform environmental work.

2. No project performance information was collected.

3. Current processes did not differentiate the value and performance of vendors for new contracts.

4. Increased pressure on ADEQ to utilize all resources provided.

\section{The Best Value Performance Information Procurement System (BV PIPS)}

Teena Zeigler (ADEQ Procurement Director) met Dr. Dean Kashiwagi (Director of the Performance Based Studies Research Group (PBSRG) at Arizona State University (ASU)) at a National Institute of Governmental Purchasing (NIGP) conference held in August 2013. Dr. Dean presented a solution developed to improve the performance of professional services called the Best Value Performance Information Procurement System (PIPS). He presented results of multiple tests in the construction and IT industries. ADEQ identified this as a potential solution to their problem, due to the similarity and the complexity that construction and IT projects have with environmental projects.

Some of the impacts of the BV PIPS are as follows (Kashiwagi, 2013; PBSRG, 2015):

- $1800+$ projects and services delivered / \$6.4B of projects and services delivered.

- $123+$ unique clients [government and private sectors].

- $\quad 98 \%$ customer satisfaction / 9.0 (out of 10) client rating of BV PIPS model.

- Decreased the cost of services on average by $31 \%$.

- Vendors were able to offer the client/owner $38 \%$ more value.

- $\quad$ Decreased client efforts by up to $79 \%$.

In 2008, a CIB Task Group (TG61) performed a worldwide study identifying innovative construction methods with documented high performance results. The study filtered through more than 15 million articles and reviewed more than 4,500 articles. In the end, the study found only 16 articles with documented performance results. The BV PIPS was one of three construction methods found in those articles, totaling $75 \%$ (12 of 16) of the articles (Egbu, et. al., 2008; Michael, et. al., 2008).

The process consists of three major phases (selection, clarification, and execution). During selection, vendors compete based on their level of expertise. The vendor that is highest ranked move into clarification. In clarification, the vendor is required to explain how they will accomplish work efficiently and with high customer satisfaction. They are required to identify performance metrics that they will track throughout the contract. Upon approval from the client, the vendor moves into the execution phase. In this phase, vendors will receive projects as work is required. Currently the BV PIPS is used mainly as a procurement and risk management system. The process has project management applications; however, it has not previously been used as a project management system.

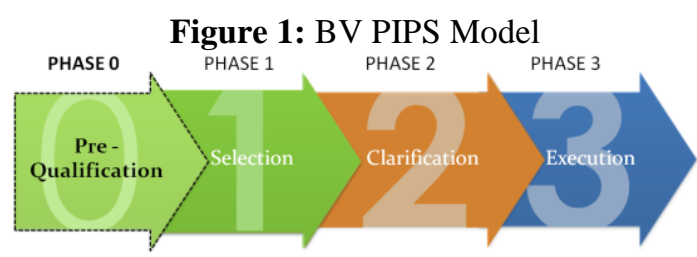

\section{Hypothesis}

Due to the success of the BV PIPS in improving project performance, using the principles of the BV PIPS could increase the efficiency and productivity of ADEQ's project managers and assist in delivering high performing project results.

\section{Methodology}

To confirm the hypothesis, the following research steps were taken:

- Identify the project management principles used in the BV PIPS process to develop the Best Value Project Management Model (BV PMM).

- Perform a research case study implementing the new PM model on ADEQ projects for one year.

- Document implementation of the new project management model.

- Document the results of the new project management model.

- Compare the results of ADEQ's traditional PM model with the new BV PMM.

DOI: $10.9790 / 487 X-18090297102 \quad$ www.iosrjournals.org




\section{The Best Value Project Management Model}

A literature research was performed identifying the project management (PM) principles found in the BV PIPS process. The following publications and sources were used:

1. 200+ academic conference and journal papers.

2. The Information Measurement Theory and Best Value Approach manuals.

The BV PIPS was derived from the principles of the Industry Structure (IS) model and Information Measurement Theory (IMT). The IS was developed in 1991, and proposed that the buyer or end user, may be the major source of project cost and time deviation. The IS proposes that a project manager should not manage, direct, and control others. They should utilize the expertise of others on a project. Utilizing BV PIPS involves the following changes to a project manager's role:

1. Identify an expert to perform the project.

2. Ensure Quality Assurance and not Quality Control. The project manager is responsible for ensuring the expert has a plan, the plan is understandable to everyone, and they have a way to measure the quality of their work throughout the project.

3. Minimize the decision making of the project manager. The project manager requires the expert to take control of the project and make any decisions required.

4. Coordinate and complete any tasks outside of the expert's scope of work.

The Information Measurement Theory (IMT), which uses natural laws and logic to explain reality and identify expertise and value, was also used to develop the BV PIPS system. The main idea IMT proposes is that one individual has no impact, influence, or control on other individuals, it supports the IS in minimizing management, direction, and control (MDC). An expert is identified as an individual with more information in a certain area. Hence, the more expertise someone has, the less they believe in the ability to control or influence other people, and the more they believe that they control their own life and have $100 \%$ accountability for it. Figure 2 shows the difference between the belief in influence and control versus the belief in no-influence and no-control. On the left side, the arrows are facing out showing that the individual is accountable for his life and his environment. On the right side, the arrows are facing in showing that the individual believes their environment and life is responsible for what happens to them. The corresponding characteristics of each belief are also found in Figure 2.

Figure 2: No-Influence Vs Influence Model

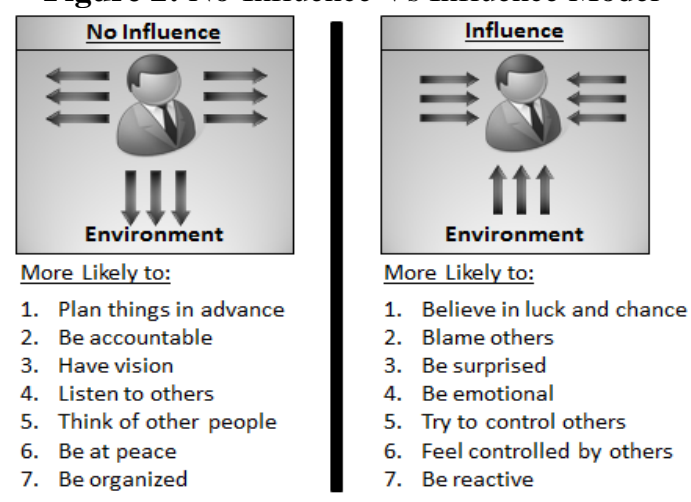

The new BV PMM identifies that the role of the project manager changes from being a manager to now being more of a leader. A manager being an expert that directs others and makes decisions on project (PMI, 2000), and a leader being one that aligns expertise. The manager requires technical knowledge and understanding. The leader requires an ability to use the expertise of others. To make this transition the IS and IMT identify the following requirements for the new model:

1. Due to the project manager no longer being the expert all communication must be non-technical.

2. The project manager must ensure and require the vendor to simplify the project and create transparency.

3. All efforts must be measured. Measurements must be simple, understandable, and non-technical. Measurement enables the project manager to know the level of performance of the expert.

The literature research identified the following characteristics of the BV PMM, derived from the BV PIPS (PBSRG, 2015):

1. Utilize expertise - Align vendors and personnel with projects that fit their expertise.

2. Minimized MDC (meetings, decisions, reports, inspections, and communications). 
3. Non-technical communication - simple and non-technical performance metrics.

4. Quality assurance - ensure that the expert has a plan before they begin a project and they can explain the progress and changes to the plan throughout the execution of the project.

5. Transparency - all stakeholders have access to all project information and can understand the information without an explanation.

\section{ADEQ WQARF Implementation of BV PMM}

In January 2014, ADEQ partnered with Arizona State University, for training, mentorship and assistance, in the implementation of the BV PMM, for the delivery of their professional services on their environmental assessment and remediation projects. The new model proposed the replacement of management, direction, and control (MDC) with the utilization of expertise. The effort would develop a project management structure that would use performance metrics and non-technical communication to create transparency and increase the accountability, value of expertise, and efficiency of the entire supply chain of professional environmental services.

ADEQ chose to test the BV PMM in their Remedial Projects Unit (RPU), on its Water Quality Assurance Revolving Fund (WQARF) ASRAC indefinite delivery indefinite quantity (IDIQ) contract. The ASRAC contract had 10 vendors that could perform work for the department. This department was responsible for identifying, assessing, and cleaning up soil, groundwater, and surface water sites contaminated with hazardous substances. The unit conducts these efforts throughout Arizona with support from state funds. The program also oversees privately funded cleanup efforts. Before the BV PMM was implemented, the ADEQ project managers were given training to help them understand the change in their roles.

The five PMM characteristics were summarized into three in the following order:

1. Utilize expertise / Minimize MDC

2. Transparency / Metrics

3. Quality Assurance

\section{Utilize Expertise/Minimize MDC}

Utilizing expertise is one of the most difficult leadership characteristics for traditional project managers to adhere to (Kashiwagi, 2013, PBSRG, 2015). It requires the project managers to understand that they must minimize MDC. It requires the project manager to turn over the decision-making and accountability for the project to the vendor (expert). The project managers were only able to provide the experts an objective and estimated budget. They were no longer required to manage, direct, and control the project set up through completion. Instead they were only required to ask questions of the expert when they did not understand.

For example, in the traditional system, the project manager was in control of the identification and creation of projects for each site they managed. They identified the scope of work, schedule, and budget for each site, then identified which vendor would work on the project. In the new system, all the vendors were initially assumed to be experts, they equally distributed the work amongst the 10 ASRAC vendors using a round robin [rotating] selection process. This was done upfront before an award of contract was made for any site. When an expert was assigned to a site, they were required to move through a clarification period. During the clarification period, they would be required to develop a scope of work, schedule, budget, identify risks that they did not control, and how their efforts would advance the site toward cleanup and eventually de-listing [process of closing a WQARF site]. During the clarification period, the ADEQ project manager was only able to ask questions and raise concerns about the direction of the project, and not MDC. Assuming the ADEQ project manager was satisfied with the expert vendor's plan, they would award the contract.

\section{Transparency/Metrics}

Before the implementation of the BV PMM, ADEQ was having difficulty with the following:

1. Identifying internal processes and contractor efficiency.

2. Identifying and utilizing expertise.

3. Identifying projected spend rates of program budget.

4. Upper management knowing the performance of their project managers.

The BV PMM, was able to help ADEQ create an environment of transparency and increase the accountability by producing the following:

1. Developed a custom website to post all project information and performance.

2. Developed a custom project report, called the Weekly Risk Report (WRR), which measures deviation of each project in terms of cost and schedule. 
3. Developed a custom management report, called the Director's Report (DR), which is a compilation of all RPU project performance, prioritizes the projects by risk, budget [spend rate and change orders], and internal reports interpreted from collected data.

By creating transparency within the internal processes, ADEQ was able to better manage their budget and accurately project their costs. Additional, internal process improvements consisted of the following:

1. Updated the task order selection process with documented performance information.

2. Worked with RPU Business Specialist to simplify WQARF budget that assisted upper management in financial decision making.

3. Created a dispute system that uses ASU as a non-bias third party to help facilitate and resolve any issues or confusion raised by vendors.

4. Adjusted and simplified change order process. Created new documentation for change order approval and documentation.

5. Simplified invoice process, and educated RPU project managers on system. It also began to identify vendors who were not invoicing ADEQ quickly, and how their project managers could minimize it in the future.

\section{Quality Assurance}

Due to the role change of the project manager from a manager to a leader, the project manager no longer needed to perform Quality Control (QC) activities. QC activities included:

1. Inspection of the vendor's work (Deming, 1982).

2. Explain to the vendor when work did not meet the technical standard and ensure that they fixed the work in a timely manner.

The elimination of the above activities made the ADEQ project managers the most nervous. The main concern they had was: How do you ensure the vendor's work meets the minimal quality standards? The BV PMM does this through quality assurance (QA). Quality assurance is ensuring that the vendor has a plan, is following the plan, and is documenting the performance of the project, throughout the entire project, not just at the end. If a client performs QA correctly, the vendor will always produce high quality work. The new responsibilities of the project manager were simplified to five simple activities:

1. Ensure vendor completes all clarification documents and they make sense.

2. Ensure WRR is accurate (schedule, risks, cost schedule).

3. If the WRR is inaccurate or does not make sense, ask the vendor to explain / correct.

4. Ensure vendor completes work before invoices are paid.

5. Copy ASU on all activities so documentation can occur.

\section{BV PMM Case Study Results}

According to the newly appointed RPU Manager, Scott Green, he identified the BV PMM as a success. Due to ADEQ's Lean initiative to introduce new models like the BV PMM, it helped support the improvement of internal processes and create transparency. Table 1 compares the overall performance of ADEQ's traditional and best value implementations. The BV PMM approach assisted ADEQ with the following:

- Reduced the amount of preparation needed to select and monitor vendors.

- Forced the expert vendor to become accountable and identify their level of expertise.

- Required the expert to make things simple enough that even non-experts can understand.

- Required the expert vendor to take control over their project, which was to their benefit in the end by reducing client MDC.

Table 1: Overall ADEQ Performance

\begin{tabular}{|l|l|l|l|}
\hline No. & Criteria & Traditional & Best Value \\
\hline 1 & Total \# of projects & 69 & 60 \\
\hline 2 & Total cost of projects & $\$ 5.5 \mathrm{M}$ & $\$ 5.6 \mathrm{M}$ \\
\hline 3 & \% of projects Scopes of Work completed in fiscal year & $50 \%$ & $99 \%$ \\
\hline 4 & \# of ADEQ PMs to manage projects & 7 & 5 \\
\hline 5 & Customer satisfaction of vendor performance & $6.9 / 10$ & $8.4 / 10$ \\
& & & D1 (7) D3 (9) \\
\hline
\end{tabular}

Notes: Data was adjusted due to project de-scoping (24 projects, $\$ 1.2 \mathrm{M}(17.32 \%), 355$ days (10.14\%) ADEQ PMs were reduced by 2, due to leaving ADEQ.

D1 = Discipline 1 (Assessment and Characterization); D3 = Discipline 3 (Remediation) Activities 
Tables 1 shows the overall WQARF program performance. After 8 months of implementing the BV PMM, the author identified the following dominant observations:

- $\quad$ ADEQ PMs increased work capacity by $22 \%$.

- Vendors performed $102 \%$ more work in $33 \%$ less time.

- $\quad$ ADEQ customer satisfaction increased by $22 \%$.

\section{Lessons Learned:}

- $\quad$ BV PMM system is difficult to implement in an organization.

- $\quad$ Need to have visionaries in the organization to become successful.

- $\quad$ You cannot expect people to change.

- $\quad$ The structure (rules and metrics) are critical.

- Transparency creates vision and people doing the "right" thing.

- $\quad$ Project manager of the future is a leader who aligns resources and utilizes expertise.

- $\quad$ WRR was a significant tool used to help create transparency on all task orders.

\section{Conclusion}

ADEQ is implementing an advanced and theoretically sound best value project management model (BV PMM) to transform the traditional approach of project management from a price-based to a best value environment. The major objectives included minimization of management, direction, and control, the transfer of risk and control to vendors who can minimize the risk, measurement of performance of the vendors and the ADEQ agency, and to measure an increase in performance and value of the services being delivered. A core group of visionaries are attempting to transform the organizational approach from a management of personnel approach to a systems management approach, where performance measurements drive the alignment of resources. This BV PMM has aligned well with ADEQ's ongoing internal process improvement initiatives.

\section{References}

[1]. AFP. (2014). Panama Canal claims $\$ 737$ million in cost overruns -. Retrieved September 11, 2015, from http://www.ticotimes.net/2014/12/26/panama-canal-claims-737-million-in-cost-overruns

[2]. Arizona Department of Environmental Quality (ADEQ) (2015). About ADEQ. Retrieved from: http://www.azdeq.gov/function/about/index.html

[3]. Bo-Jie, F., Bing-Fang, W., Yi-He, L., Zhi-Hong, X., Jing-Hua, C., Dong, N., \&... Yue-Min, Z. (2010). Three Gorges Project: Efforts and challenges of the environment. Progress in Physical Geography, 34(6), 741-754.

[4]. Buntaine, M. T., \& Parks, B. C. (2013). When Do Environmentally Focused Assistance Projects Achieve their Objectives? Evidence from World Bank Post-Project Evaluations. Global Environmental Politics, 13(2), 65-88.

[5]. Deming, EW. (1982). Out of the Crisis, Massachusetts Institute of Technology, Cambridge.

[6]. Egbu, C., Carey, B., Sullivan, K \& Kashiwagi, D. (2008). Identification of the Use and Impact of Performance Information Within the Construction Industry Rep, The International Council for Research and Innovation in Building and Construction, AZ.

[7]. Esty, D. C., \& Porter, M. E. (2005). National environmental performance: an empirical analysis of policy results and determinants. Environment and Development Economics. Retrieved from http://doi.org/10.1017/S1355770X05002275

[8]. Filipovich, J. (2001). Destined to Fail: Forced Settlement at the Office du Niger, 1926-45. The Journal of African History, 42(2), 239-260.

[9]. Fisher. (2013). Why Environmental Impact Assessments Fail to Protect Rivers. Retrieved September 11, 2015, from http://www.internationalrivers.org/resources/why-environmental-impact-assessments-fail-to-protect-rivers-7885

[10]. Fu, B.-J., Wu, B.-F., Lü, Y.-H., Xu, Z.-H., Cao, J.-H., Niu, D., Zhou, Y.-M. (2010). Three Gorges Project: Efforts and challenges for the environment. Progress in Physical Geography.

[11]. IEG. (2013). IEG World Bank Project Performance Ratings| Data. Retrieved September 11, 2015, from http://data.worldbank.org/data-catalog/IEG

[12]. International Rivers. (2005). Lesotho Highlands Water Project: What Went Wrong? Retrieved September 11, 2015, from http://www.internationalrivers.org/resources/lesotho-highlands-water-project-what-went-wrong-4060

[13]. Kashiwagi, J. (2013). Dissertation. "Factors of Success in Performance Information Procurement System / Performance Information Risk Management System.” Delft University, Netherlands.

[14]. Macek, N. (2006). Right-of-Way and Environmental Mitigation Costs - Investment Needs Assessment. NCHRP Project 2024(54)B.

[15]. Michael, J., Sullivan, K. and Kashiwagi, D.T. (2008). "Leadership Based Project Management Model Tested on Food Services at Arizona State University" 4th Scientific Conference on Project Management (SCPM) \& 1st International Project Management Association (IPMA) / Mediterranean Network (MedNet) Conference on PM Advances, Training \& Certification in the Mediterranean, Chios Island, Greece, pp.234-238.

[16]. Padgett, T. (2014). Expanding the Panama Canal: The Problem Is Money, Not Mosquitoes. Retrieved September 11, 2015, from http://www.npr.org/sections/parallels/2014/05/30/317360379/expanding-the-panama-canal-the-problem-is-money-not-mosquitoes

[17]. PBSRG (2015). Performance Based Studies Research Group. Retrieved August, 2015 from PBSRG Web site: http://pbsrg.com/overview/documented-performance

[18]. Project Management Institute (PMI). (2000). A Guide to Project Management Body of Knowledge. Project Management Institute. Newton Square, Pennsylvania. Retrieved from http://www.cs.bilkent.edu.tr/ cagatay/cs413/PMBOK.pdf

[19]. Reuters. (2009). China says Three Gorges Dam cost \$37 billion. Reuters.

[20]. Vaughan, W. J., \& Ardila, S. (1993). Economic Analysis of the Environmental Aspects of Investment Projects. Inter-American Development Bank. Retrieved from http://publications.iadb.org/handle/11319/6300 